\title{
Controlling factors of matrix acidizing potential of low permeability clastic reservoir in faulted lacustrine basin
}

\author{
Ningning $\mathrm{Xu}^{1,2, *}$, Yongshi Wang ${ }^{3}$, Shoupeng Zhang ${ }^{2}, \mathrm{Bo} \mathrm{Li}^{2}$, Zhengwei Fang ${ }^{2}$ \\ ${ }^{1}$ Postdoctoral Scientific Research Station, Sinopec Shengli Oilfield Company, Shandong Dongying 257000, China \\ ${ }^{2}$ Research Institute of Petroleum Exploration and Development, Sinopec Shengli Oilfield Company, Shandong Dongying, 257022, China \\ ${ }^{3}$ Sinopec Shengli Oilfield Company, Dongying 257000, Shandong, China
}

\begin{abstract}
Based on constant rate mercury injection experiment, casting thin section identification, scanning electron microscope observation, clay mineral X-ray and rock specific surface area analysis, the controlling factors of matrix acidizing potential of low-permeability sandstone reservoir in fault depression lacustrine basin were determined from three aspects: pore filling, throat filling and pore-throat combination characteristics. It is concluded that provenance controls the plane partition of reservoir pore fillings. Burial depth controls the longitudinal zoning of key filling material in reservoir throat. The difference of rock structure in sedimentary facies - microfacies controlling zone leads to the change of pore-throat assemblage pattern. The matrix acidizing scheme of low permeability sandstone reservoir in fault depression basin can be formulated according to the law of "provenance zoning, buried depth zoning and being controlled by microfacies in zone", and the implementation scheme of pre-acid, main acid and post-acid can be put forward respectively. This method can effectively promote the integration process of exploration and development of low permeability clastic reservoir in mature exploration area.
\end{abstract}

\begin{abstract}
Keywords: low permeability; matrix acidization; pore-throat structure; Bonan Sag; faulted lacustrine basin; integration process of exploration and development.
\end{abstract}

\section{Introduction}

In recent years, the increasing demand for oil and gas exploration and production has led to a shift in direction and focus towards unconventional oil and gas resources. Among them, low permeability clastic reservoir is the most widely distributed, most deeply studied and most realistic. At the same time, the integration of exploration and development has gradually become an important concept and policy to improve oil and gas productivity for mature oil and gas fields in the middle and later stage of development. The low permeability clastic reservoirs of continental lacustrine distributed in the Neogene of Bohai Bay Basin have gradually changed from reserve to dominant resource type. Low permeability reservoirs in fault depression basins are characterized by diverse provenance, large burial depth and diverse sedimentary facies, which make the reservoir structure and type complex[1-7]. At the same time, the low-permeability reservoir has a small pore throat radius, and the types and crystal shapes of the impurity base and cement filled are diverse, leading to prominent water-sensitive and fastsensitive characteristics[8-11], which seriously affects the later mining and development.

Matrix acidification is one of the most commonly used stimulation treatments. Matrix acidification is the solution or dissolution of pore-throat filling material on the basis of ensuring the basic structure of rock, thus increasing reservoir permeability. Therefore, for matrix acidizing of low permeability sandstone reservoir, the integrated thinking of exploration and development is how to establish the connection between reservoir geology, development geology and oilfield chemistry. How to define and evaluate the potential of matrix acidizing transformation of low permeability sandstone reservoir from the perspective of reservoir geology, and evaluate the reservoir by the transformable ability, and then put forward that the targeted acidizing liquid system is the work that needs to be completed at present.

At present, the fluid system used for matrix acidification of sandstone reservoirs is more based on empirical conclusions. From the original acidizing formula guide in 1983 [12] to the acidizing formula Guide in 2001[13], reservoir evaluation is mainly based on permeability, reservoir mineralogical composition (feldspar, clay minerals, etc.) and other parameters. Different parameters are isolated from each other, and the research methods and achievements of reservoir geology cannot be reflected. Therefore, how to use the research method of reservoir geology to analyze and evaluate the transformation potential of reservoir matrix acidification, and to clarify its main control factors and control mode is the key of the

\footnotetext{
Corresponding author: 418048012@qq.com
} 
research. The low permeability clastic reservoir in the northern bonan sag of Jiyang Depression is selected to analyze and summarize the controlling factors and control modes of matrix acidizing potential.

\section{Controlling factors of acidizing potential of low permeability sandstone matrix}

The characteristics of low permeability sandstone reservoir in continental faulted lacustrine basin are complex and diverse. It is concluded that these geological characteristics are determined by three factors: (1) the provenance controls the plane partition of reservoir pore fillings (calcite, andolomite, siliceous and pyrite, etc.); (2) Burial depth controls the longitudinal zonation of reservoir throat fillers (kaolinite, illite, chlorite and mixed layer minerals, etc.) and (3) the rock structure differences (sorting, rounding, contact mode, etc.) within the sedimentary facies - microfacies control zone, and leads to the change of pore-throat assemblage mode (Fig. 1).

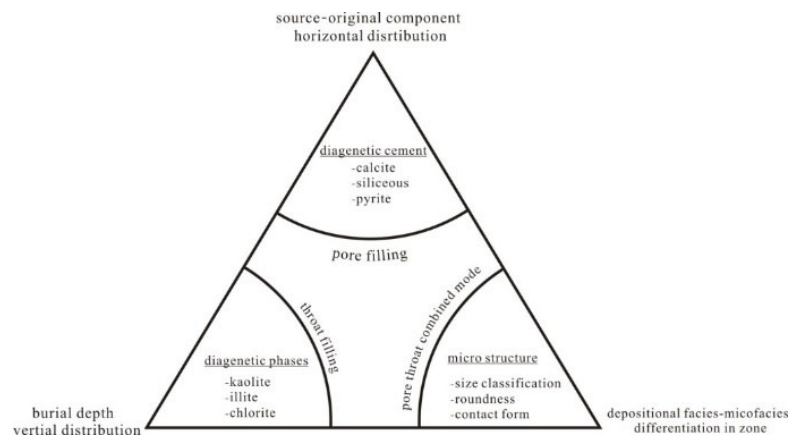

Fig.1 Controlling factors of matrix acidizing potential of low permeability reservoir

\subsection{Provenance controls the plane partition of pore fillings}

The differentiation of pore and throat radius is obvious in low permeability sandstone reservoir. The relatively developed pore types include primary intergranular pore, intergranular residual pore, intragranular dissolved pore, intergranular dissolved pore and fracture pore. The pore fillings mainly include the original sedimentary complex and the types of diagenetic alteration (such as gray matter complex recrystallization), siliceous cementation in early diagenetic stage and calcite - andolomite cementation in middle diagenetic stage.

First, the aim of matrix acidification of sandstone is to chemically remove or dissolve minerals from the pore throat. The original deposits and alteration products are usually argillaceous or gray complexes, and often contain clay components and adsorbed iron. At the same time, after a long time of compaction, they often appear as relatively dense occurrence state. Therefore, the acidizing effect of hydrochloric acid or soil acid in common use is relatively general, so for pore filling, matrix acidizing pays more attention to the diagenetic and cementation minerals in it. Secondly, compared with the throat (radius $<5 \mu \mathrm{m}$ ), the pores are filled with authigenic minerals formed in the diagenetic stage. Because the pore space is larger, it is easier for the fluid to crystallize out minerals. The cemented rock forming minerals in the pores are significantly affected by the original particle composition of the reservoir and the early synsedimentary fluid. By comparing different provenance areas in the study area, it is found that the types of reservoir pore fillings are obviously controlled by provenance.

\subsection{Burial depth controls the longitudinal zoning of clay mineral assemblage pattern in reservoir throat}

The throat radius of low permeability sandstone reservoir is less than $5 \mu \mathrm{m}$, and the filling minerals are mainly illite, Aemon mixed layer and chlorite. Montmorillonite or chloritic coatings are most easily formed on the surface of particles during the sedimentation-transport process and in the codeposition period. During the syndepositional and early diagenetic stages, the particles began to contact with each other in the form of point, point and line, and this envelope became one of the earliest filling types of larynx. In the early diagenetic stage, the diagenesis type of reservoir is early siliceous cementation. Reservoir porosity before early diagenesis was about $39 \%$, and after compaction, it decreased by $20 \% \sim 30 \%$ to $10 \% \sim 15 \%$. After diagenesis, porosity varies within a small range. This suggests that compaction, porosity reduction and diagenesis during early diagenesis largely determine the type of filling in the throat $(<5 \mu \mathrm{m})$.

According to the results of previous studies, the laryngeal types mainly include pore shrinkage part, variable section contraction part, flaked - curved flaked laryngeal and bundle - shaped laryngeal. The first three are the results of different degrees of contact between particles, bundle throat mainly refers to the microscopic channels in the intergranular complex. Therefore, rock transport and deposition, synsedimentary and early diagenetic stages are the main causes of the formation of throat filling types. Among them, different types of clay mineral original envelope and late diagenetic variation, and early siliceous cements formed in synsedimentary and early diagenetic stages are the main types of throat filling. Because of the variety of clay mineral types, crystal shape and complex sensitivity characteristics, it has become the most important object in matrix acidification.

Clay minerals, especially in sandstone reservoirs, undergo a series of complex diagenetic evolution. Different basins have relatively stable evolution patterns in different layers. The evolution of clay minerals in sandstone reservoirs of the 4th Member of Shahejie formation in Jiyang Depression is a conventional montmorillonite - Illite mixed layer and kaolinite - chlorite/illite evolution model. There are different assemblage patterns of clay minerals in different provenances and layers at different depths. 


\subsection{Sedimentary facies-microfacies control rock structure difference leading to the change of pore-throat combination model.}

Provenance and burial depth control the pore and throat filling material of sandstone reservoir, and the size, connectivity and combination pattern of pore and throat space are also very important aspects to evaluate the acid solution reconstruction potential of reservoir. Burial depth has an influence on it, but the influence is universal, and the reservoir is subjected to the same compaction intensity within the same burial depth range. The real difference of pore throat spatial pattern in low permeability sandstone reservoir is sedimentary facies - microfacies. Because of reservoir at the beginning of the diagenetic process, transportation, deposition and consolidation of the rock structure elements including grain size, sorting, psephicity, contact between particles, as well as the mechanical or chemical differentiation of primitive components such as particles and the differences of the type and content of mixed base, makes the reservoir showed significant difference.

The sedimentary facies of low permeability sandstone in the study area mainly include fan delta, turbidite fan and nearshore subaqueous fan. The sedimentary environments of the three facies types are quite different, which makes them have different rock structure characteristics. The combination of provenance, depth and sedimentary facies and microfacies control the plane partition of diagenetic cementation, the longitudinal zonation of clay mineral assemblage model and the pore throat space configuration. As a result, the low permeability sandstone reservoir has a different specific surface area.

\section{Conclusion and Enlightenment}

(1)Taking Bonan Sag as an example, a "ternary" control model of matrix acidizing potential of low-permeability sandstone reservoir in faulted lacustrine basin was proposed, that is, the plane partition of pore fillers (calcite, dolomite, siliceous and pyrite, etc.) controlled by provenance; Burial depth controls the longitudinal zonation of key filling materials (kaolinite, illite, chlorite and mixed layer minerals) in the reservoir throat and the rock structure differences (sorting, rounding, contact mode, etc.) in the sedimentary facies - microfacies control zone, and leads to the change of pore-throat assemblage pattern.

(2) Based on the "three-step" control mode of reservoir matrix acidizing potential, according to the law of "provenance zoning, buried depth zoning and microfacies control within the zone", matrix acidizing can take a "three-step" plan formulation process. Firstly, the modification method (acid pressure or acidification) and the type and concentration of pre-acid were determined according to the plane partition characteristics of pore fillings caused by the difference of provenance. Secondly, the type and concentration of main acid were determined according to the longitudinal zonation of key fillings in throat caused by burial depth. Finally, it is adjusted according to the difference of pore throat conFiguration patterns caused by sedimentary facies and microfacies in sand group or single sand body acid system.

\section{Acknowledgments}

This work was financially supported by China Postdoctoral Science Foundation Funded Project (Project No.2019M662438).

\section{References}

1. Zhang Shuncun, Chen Lihua, Zhou Xinxian, et al. Sedimentary model of the Permian sandy conglomerate in the footwall of the Kebai Fault, the Junggar Basin[J]. Oil \& Gas Geology, 2009, 30(06):740-746.

2. Zheng Zhan, Wu Shenghe, Xu Changfu, et al. Lithofacies and reservoirs of allluvial fan in the Lower Keramay Formation in the block- 6 of Karamay oilfield, the Junggar Basin[J]. Oil \& Gas Geology, 2010, 31(04):463-471.

3. Huang Huicai, Liu Kai. Discussion on the present situation and problems of water flooding development in the conglomerate reservoir of Yanjia oilfield[J]. Nei Jiang Science \& Technology, 2009, 30(4): 91-92.

4. Zhang Jing, Wang Weifeng, Rong Qihong, et al. Deep-Water Turbidite Fan Deposits and Relation to Hybrocarbon of the Upper Sha-4 of Shahejie Formation at Yong-55 Block in Dongying Sag[J]. Journal of Jilin University (Earth Science Edition), 2007, 37 (03): 519-524.

5. Zhang Shuncun, Jiang Huan, Zhang Lei, et al. Genetic Analysis of the High Quality Reservoir of Triassic Baikouquan Formation in Mabei Region, Junggar Basin[J]. Acta Sedimentologica Sinica, 2014, 32 (06): 1171-1180.

6. Shao Hongmei, Liu Zhaojun, Wang Cheng, et al. Diagenesis and pore evolution of deep sandstone in north of Songliao Basin[J]. Global Geology, 2005, 24(01): 58-62.

7. Wang Tinghao, Yan Deyu, Huang Wenhui, et al. Characteristics of conglomerate reservoir of Kexia Formation in Liuzhong area of Karamay oilfield[J]. Journal of Northeast Petroleum University, 2014, 38(3): 31-41.

8. Soeder D, Randolph P. Porosity, permeability, and pore structure of the tight Mesaverde Sandstone, Piceance Basin, Colorado. SPE Formation Evaluation [J], 1987, 2(2): 129-136.

9. Reinicke A, Rybacki E, Stanchits S, et al. Hydraulic fracturing stimulation techniques and formation damage mechanisms-Implications from laboratory testing of tight sandstone- proppant systems[J]. Chemie der Erde - Geochemistry, 2010, 70(S3):107117. 
10. Li Daopin. Introduction to development of low permeability oil fields[J]. Petroleum Geology and Oilfield Development in Daqing, 1997, 16 (3):33-37.

11. Jiang Lingzhi, $\mathrm{Gu}$ Jiayu, Guo Binchegn. Characteristics and Mechanism of Low Permeability Clastic Reservoir in Chinese Petroliferous Basin[J]. Acta Sedimentologica Sinica, 2004, 22(1): 13-18.

12. Crowe C, Masmonteil J, Thomas R. Trends in matrix acidizing. Oilfield Review [J], 1992, 4(4): 22-40.

13. Kalfayan L J, Metcalf A S. Successful Sandstone Acid Design Case Histories: Exceptions to Conventional Wisdom[C]. 2000. 